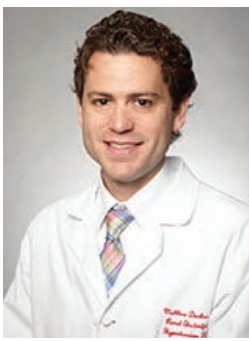

M. G. Denker, M.D.

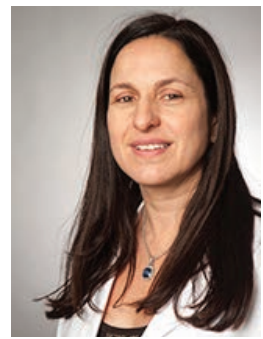

D. L. Cohen, M.D.

\title{
RESISTANT HYPERTENSION AND RENAL NERVE DENERVATION
}

\author{
Matthew G. Denker, M.D.; Debbie L. Cohen, M.D. \\ University of Pennsylvania, Perelman School of Medicine, Philadelphia, Pennsylvania
}

\begin{abstract}
Patients with resistant hypertension are a subgroup of the hypertensive population that are at even greater risk of cardiovascular outcomes. Therapeutic options for these patients are limited to antihypertensive medications. However, renal denervation (RDN) is a novel nonpharmacologic intervention that involves a catheter-based ablation of the sympathetic nerves within the renal artery wall. The procedure initially showed promise with remarkable blood pressure reductions until the pivotal SYMPLICITY HTN-3 trial failed to demonstrate superiority of RDN over control. This trial was notable for a substantial placebo effect and an attenuated response to RDN. These findings, which contradicted those of prior studies, have raised numerous questions, including whether adequate RDN occurred in those patients. Further research is planned to resolve some of these questions and to clarify the role of RDN in treating patients with resistant hypertension.
\end{abstract}

\section{Introduction}

Hypertension is highly prevalent and is associated with considerable risk of cardiovascular $(\mathrm{CV})$ disease and mortality. ${ }^{1}$ Though blood pressure (BP) control can reduce these risks, BP control rates remain suboptimal. ${ }^{2}$ Resistant hypertension affects $10 \%$ to $15 \%$ of patients with hypertension and is defined as uncontrolled BP despite the use of at least three antihypertensive medications, one of which is a diuretic, prescribed at maximally tolerated doses, or controlled BP with the use of at least four medications. ${ }^{3}$ Patients with resistant hypertension have an even greater risk of CV outcomes than those with less-severe hypertension. ${ }^{4}$ The therapy for resistant hypertension usually consists of lifestyle modifications and the addition of more antihypertensive medications. However, medication adherence is inversely related to the number of prescribed medications, ${ }^{5}$ thus contributing to lack of BP control in patients with resistant hypertension.

In the past decade, renal denervation (RDN) has emerged as a potential therapeutic option for patients with resistant hypertension. RDN is a catheter-based radiofrequency ablation of the afferent and efferent sympathetic nerves within the wall of the renal arteries. While the therapy had shown promising results in early trials, the pivotal SYMPLICITY HTN-3 trial failed to meet its primary efficacy endpoint, which led to a suspension of further investigation in this field. A number of potential explanations for the trial's negative findings have been proposed, and interest in this unique therapy persists.

\section{Sympathetic Nervous System Activity in Hypertension}

Sympathetic nervous system (SNS) hyperactivity occurs in hypertensive patients, ${ }^{6,7}$ and the degree of SNS activity is associated with the severity of BP elevation. ${ }^{8,9}$ SNS activity may also modulate nocturnal BP dipping. ${ }^{10}$ Increased adrenergic activity not only contributes to the development and maintenance of hypertension but also is more pronounced among patients with hypertension-related end-organ damage, independent of $\mathrm{BP},{ }^{11,12}$ suggesting a possible pathogenic role for SNS activity in hypertensive complications. Locally at the renal level, efferent sympathetic outflow to the kidneys leads to decreased renal blood flow, renin release, and sodium retention while afferent sympathetic fibers send signals to the brain to stimulate central sympathetic activity and contribute to neurogenic hypertension (Figure 1). ${ }^{13,14}$ These relationships provide a rational basis for sympathoinhibitory therapies in the management of hypertension.

Renal denervation ablates the afferent and efferent sympathetic nerves in the adventitia of the renal arteries. The device catheter is inserted percutaneously into the femoral artery and advanced into the main renal arteries under fluoroscopic guidance. After excluding renovascular abnormalities by angiography, a generator is then activated to deliver radiofrequency energy to the renal artery wall. The strategy of the procedure is to maximize nerve disruption by applying four to six ablation treatments to each renal artery with ablations spaced both longitudinally and circumferentially along the vessel wall. Each ablation lasts $\leq 2$ minutes, and the entire procedure takes about 40 minutes to complete. RDN reduces sympathetic activity both locally in the kidney and systemically, ${ }^{15,16}$ which in turn reduces renin activity and increases renal blood flow.

\section{SYMPLICITY HTN Trials}

While various catheter devices have been used for RDN and have demonstrated success (Table 1) ${ }^{17-20}$ this discussion focuses on the Symplicity ${ }^{\mathrm{TM}}$ Flex Renal Denervation Catheter (Medtronic, Inc., Minneapolis, MN). The SYMPLICITY HTN-1 trial was the first in a series of trials that used this catheter to test the antihypertensive efficacy of RDN among patients with resistant hypertension. ${ }^{21}$ This single-arm, proof-of-principle study showed that RDN led to a robust office BP reduction of 27/17 mm Hg at 12 months followup, reduced norepinephrine spillover (a measure of SNS activity), and improved nocturnal dipping. In addition, there were few 

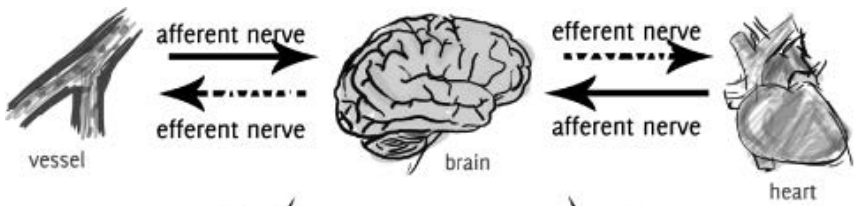
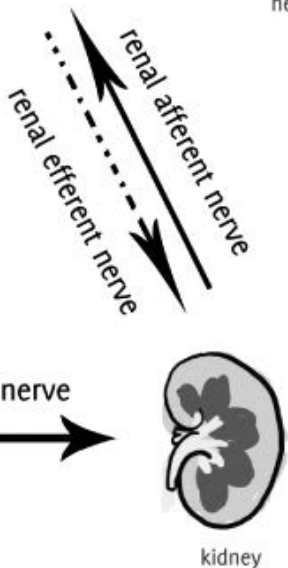

Activation of renal efferent nerves:

- Increased noradrenaline production

- Increased renal vasoconstriction

- Increased renin release

- Increased salt and water retention
Figure 1. The physiological effects of activating efferent and afferent renal sympathetic nerves. Reprinted from Huan et al. with permission from Wiley. ${ }^{14}$

\section{Activation of renal afferent} nerves:

- Increased central sympathetic outflows to various organs procedure-related complications, thus setting the stage for further studies. In 2014, the SYMPLICITY HTN-1 investigators published follow-up data on 153 patients who underwent open-labelled $\mathrm{RDN}$, reporting a remarkable mean $\mathrm{BP}$ reduction of 32/14 mm Hg that was sustained 36 months after RDN and occurred without additional antihypertensive medications. ${ }^{22}$ Interestingly, despite ablation of sympathetic nerves, heart rate was unaffected.

The SYMPLICITY HTN-2 trial was a randomized controlled trial (RCT) performed across centers in Europe, Australia, and New Zealand that randomized 106 patients with resistant hypertension to RDN plus previous medical therapy or previous medical therapy alone. ${ }^{23}$ The study showed that RDN significantly reduced office BP from 178/97 $\mathrm{mm} \mathrm{Hg}$ at baseline to $143 / 85 \mathrm{~mm}$ $\mathrm{Hg}$ at 6 months, while BP was unchanged in the control group. In addition, significant reductions in home and 24-hour ambulatory $\mathrm{BP}$ were observed in the RDN group only. After 6 months, patients in the control arm were given the option of undergoing RDN. Among the pooled patients who underwent RDN and were followed for 36 months, office BP was reduced by $33 / 14 \mathrm{~mm} \mathrm{Hg}$, consistent with the follow-up data from SYMPLICITY HTN-1. ${ }^{24}$

With momentum and enthusiasm for this groundbreaking technology growing, the largest RDN trial, SYMPLICITY HTN3, was the first to be performed in a U.S. cohort of patients with resistant hypertension and, in contrast to prior trials, involved a sham procedure in the control group. ${ }^{25,26}$ Though a greater percentage of patients in the RDN group had a clinically meaningful reduction of office-based systolic BP (SBP) of $\geq 10 \mathrm{~mm}$
$\mathrm{Hg}$ from baseline to 6 months, which was statistically significant, this trial did not meet its primary efficacy endpoint. After 6 months, office SBP was reduced by 14.1 and $11.7 \mathrm{~mm} \mathrm{Hg}$ in the RDN and control arms, respectively. Each group's BP reduction from baseline was statistically significant, but the between-group difference was not. Also, there was no statistically significant difference between treatment groups when BP was assessed by 24-hour ambulatory monitoring. Post hoc exploratory analyses identified several key variables that were predictive of BP response to RDN, including total number of ablation attempts, higher baseline office BP, use of an aldosterone antagonist, and preserved kidney function at baseline. ${ }^{27}$ Table 2 summarizes the BP responses to RDN across the three SYMPLICITY trials.

\section{Interpretations of the SYMPLICITY HTN-3 Trial Results}

The medical community and RDN device companies were disappointed and surprised by the results of SYMPLICITY HTN-3, and ongoing enrollment for subsequent studies ceased. Numerous potential explanations have been proposed for the conflicting results among these trials, including differences in study design, patient characteristics, medication adherence, or efficacy of the RDN procedure.

While SYMPLICITY HTN-2 and HTN-3 were both RCTs, HTN-2 was a less-rigorous study design since patients were not blinded to their treatment arm and did not undergo a sham procedure. Unlike the preceding studies, there was a potent placebo or Hawthorne effect in the control group of HTN-3. Among other factors, this

\begin{tabular}{|c|c|c|c|c|}
\hline Study & $\mathrm{GSR}^{\star 17}$ & EnligHTN-118 & REDUCE-HTN ${ }^{19}$ & RAPID $^{20}$ \\
\hline RDN catheter, company & Symplicity ${ }^{\mathrm{TM}}$, Medtronic & $\begin{array}{l}\text { EnligHTN'TM, St. Jude } \\
\text { Medical }\end{array}$ & $\begin{array}{l}\text { Vessix }{ }^{\mathrm{TM}}, \text { Boston } \\
\text { Scientific }\end{array}$ & OneShot ${ }^{\mathrm{TM}}$, Covidien \\
\hline No. of patients & 323 & 46 & 146 & 50 \\
\hline $\begin{array}{l}\text { Mean office SBP } \\
\text { reduction after RDN } \\
(\mathrm{mm} \mathrm{Hg})\end{array}$ & 20 & 29 & 25 & 22 \\
\hline Follow-up duration & $6 \mathrm{mo}$. & $24 \mathrm{mo}$. & $6 \mathrm{mo}$. & $12 \mathrm{mo}$. \\
\hline
\end{tabular}

Table 1. The effects of various RDN catheter devices on blood pressure. RDN, renal denervation; GSR, Global Symplicity Registry; SBP, systolic blood pressure. 


\begin{tabular}{|c|c|c|c|c|c|c|c|c|c|}
\hline \multirow[t]{2}{*}{ Trial } & \multirow[t]{2}{*}{ Design } & \multirow[t]{2}{*}{$\begin{array}{l}\text { No. of } \\
\text { patients }\end{array}$} & \multirow{2}{*}{$\begin{array}{c}\text { Mean } \\
\text { no. of BP } \\
\text { medications } \\
\text { at baseline }\end{array}$} & \multirow{2}{*}{$\begin{array}{c}\text { Mean } \\
\text { office BP } \\
\text { at baseline } \\
(\mathrm{mm} \mathrm{Hg})\end{array}$} & \multicolumn{5}{|c|}{$\begin{array}{l}\text { Mean office BP reduction after RDN } \\
\qquad(\mathrm{mm} \mathrm{Hg})\end{array}$} \\
\hline & & & & & $1 \mathrm{mo}$. & $6 \mathrm{mo}$ & 12 mo. & $24 \mathrm{mo}$ & $36 \mathrm{mo}$. \\
\hline $\begin{array}{l}\text { SYMPLICITY } \\
\text { HTN-1 }\end{array}$ & Uncontrolled & 153 & 5.1 & $176 / 98$ & $21 / 10^{*}$ & $26 / 11^{*}$ & $27 / 12^{*}$ & $30 / 13^{*}$ & $32 / 14^{*}$ \\
\hline $\begin{array}{l}\text { SYMPLICITY } \\
\text { HTN-2 23,24 }\end{array}$ & $\begin{array}{l}\text { Randomized } \\
\text { controlled }\end{array}$ & 106 & 5.2 & $178 / 97$ & $20 / 7$ & $32 / 12$ & $26 / 10^{*}$ & $30 / 11^{*}$ & $33 / 14^{*}$ \\
\hline $\begin{array}{l}\text { SYMPLICITY } \\
\text { HTN-325,26 }\end{array}$ & $\begin{array}{l}\text { Randomized } \\
\text { sham-controlled }\end{array}$ & 535 & 5.1 & $180 / 97$ & & $14 / 7$ & $19 / 8^{\dagger}$ & & \\
\hline
\end{tabular}

Table 2. Summary of findings from the SYMPLICITY HTN trials. BP: blood pressure; RDN: renal denervation.

effect may have been influenced by the large percentage of patients whose antihypertensive medications were changed during the follow-up period. Specifically, there were slightly more increases in dose or number of medications in the sham group and more decreases in dose or number of medications in the RDN group, ${ }^{27}$ possibly confounding subsequent BP measurements. Patients in HTN-3 will continue to be followed out to 5 years, and we expect that this placebo effect will diminish over time, whereas the effect of RDN should be sustained. Also, HTN-3 was performed in a U.S. cohort that consisted of a higher proportion of blacks than in other trials. Interestingly, there were no racial differences in response to the RDN procedure in HTN-3, but black patients had a more potent response to the sham procedure than non-black patients, ${ }^{27}$ which warrants further exploration.

Another area of focus in explaining the varied results of these trials is the RDN procedure itself. First, the anatomic distribution and density of sympathetic nerves within the renal artery wall are complicated (Figure 2). While there is a greater concentration of nerves in the proximal and middle segments of the artery, those in the distal segment lie closer to the lumen and are thus more susceptible to ablation. ${ }^{28,29}$ The available catheter technology limits accessibility to more complete ablation in the proximal and middle segments, and perhaps the ability to ablate the distal segment and branch renal arteries would result in more complete denervation. Further, the circumferential distribution of nerves is not uniform, such that there are more nerves in the ventral than dorsal region. Therefore, asymmetric delivery of radiofrequency energy is necessary. In the SYMPLICITY trials, the RDN procedure was performed by starting in the distal segment of the artery with successive ablations applied to the wall after rotating the catheter tip circumferentially and withdrawing proximally. However, only 19 patients in SYMPLICITY HTN-3 received ablations in all four quadrants bilaterally. ${ }^{27}$ In this small group of patients, BP reduction was similar to that observed in prior trials. Given the complicated network of nerves, there is likely a certain minimum number of ablations for the procedure to be effective. In fact, the number of ablation attempts during the procedure was associated with greater $\mathrm{BP}$ response to RDN, and a higher number of ablations did not increase the risk of adverse events. ${ }^{27}$ Also, because proceduralists lacked hands-on experience with RDN prior to the HTN-3 trial, the success of the procedure may have been influenced by the operator's level of experience. Though evidence of an operatorrelated learning curve was not detected in the data, the majority of operators in SYMPLICITY HTN-3 performed fewer than three procedures in the trial..$^{27}$ Data from the Global SYMPLICITY Registry (GSR), which consists of data from 998 patients who underwent RDN, showed that experienced operators delivered a greater number of complete 120 -second ablations per patient than
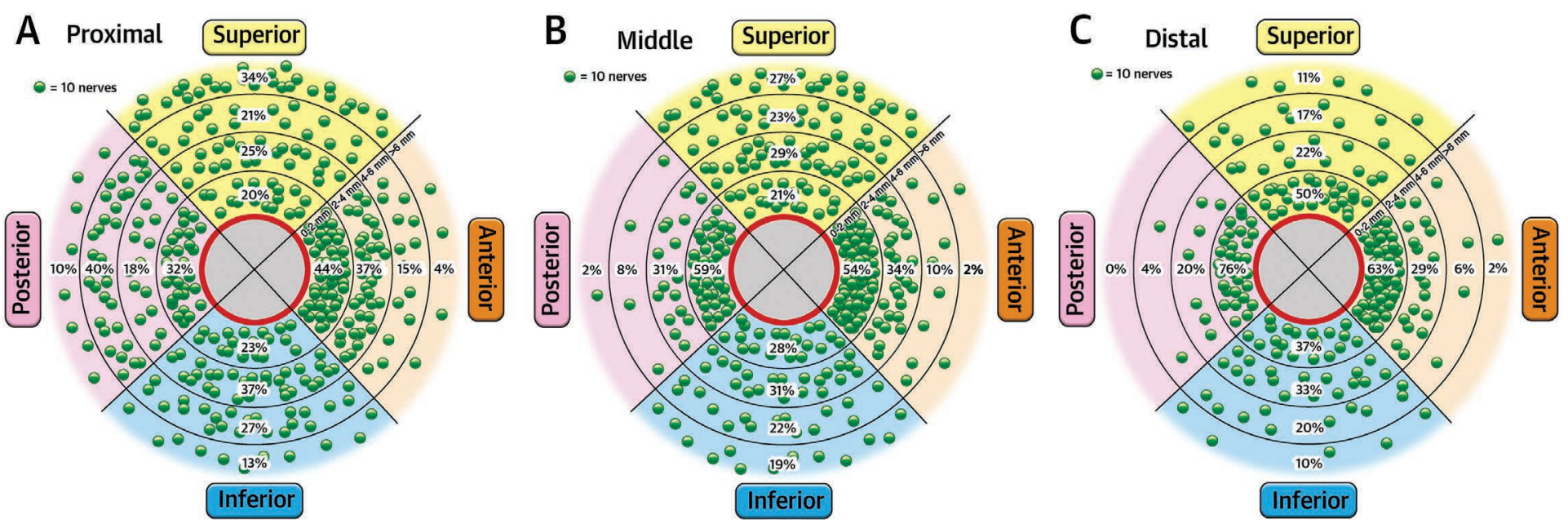

Figure 2. The distribution of renal sympathetic nerves within and along the renal artery wall. Each green dot represents 10 nerves. Percentages denote the relative number of nerves according to distance from the lumen in each cross-sectional segment of the artery wall and in (A) proximal, (B) middle, and (C) distal locations. Reprinted from Mahfoud et al. with permission from Elsevier. ${ }^{28}$ 
operators in SYMPLICITY HTN-3; patients in the GSR with resistant hypertension and baseline SBP $\geq 160 \mathrm{~mm} \mathrm{Hg}$ had a SBP reduction of $20.3 \mathrm{~mm} \mathrm{Hg} 6$ months after RDN, which was statistically significant and greater than the reduction observed in HTN-3. ${ }^{17}$

These findings highlight some of the knowledge gaps in this field and provide reasonable explanations for the differences in RDN efficacy among the SYMPLICITY trials. We believe additional studies are warranted to fill these gaps. Further catheter development may even be necessary to limit inter-individual differences in ablation success. In addition, there is currently no accepted method to assess the procedure's efficacy, and such a method could be valuable during and/or after the procedure.

Recently, Medtronic announced plans for additional research in this area with the SPYRAL HTN Global Clinical Trial Program. This program will consist of two randomized, sham-controlled trials-SPYRAL HTN-OFF MED and SPYRAL HTN-ON MEDand patients will be followed for 3 years after RDN. The former is designed to isolate the BP-lowering effect of the RDN procedure, and the latter will evaluate the effect of RDN in the presence of standardized antihypertensive medications. In addition, a newer, multielectrode catheter will be used to reduce procedure duration and allow for the simultaneous and uniform delivery of radiofrequency energy in four quadrants.

Further research is also needed to establish which patients are likely to derive therapeutic benefit from the procedure. RDN may be an attractive and useful therapy for patients with lesssevere hypertension, and two RCTs already have demonstrated a benefit of RDN in these patients, though with more modest BP reductions. ${ }^{30,31}$ Small series have even shown substantial effects on $\mathrm{BP}$ in patients with advanced chronic kidney disease ${ }^{32}$ and endstage renal disease. ${ }^{33}$

\section{Safety of RDN}

While efficacy data are conflicting among the SYMPLICITY trials, one consistent finding is the safety of RDN. The risk of procedural complications, including renal artery dissection and pseudoaneurysm, is low, and kidney function is not affected. ${ }^{17}$ Patients with preexisting renovascular abnormalities were excluded from the SYMPLICITY trials, but there have been several reports of de novo renal artery stenosis discovered during followup that were not originally reported in the results of the trials. ${ }^{34-36}$ Nevertheless, this risk is still low.

\section{Conclusions}

Resistant hypertension is associated with an increased risk of $\mathrm{CV}$ outcomes and remains a challenging condition to treat. Recently, RDN has emerged as a potential nonpharmacologic therapy for the condition and had shown promising results until the SYMPLICITY HTN-3 trial, which failed to demonstrate an incremental benefit of RDN on BP. In contrast to prior studies, HTN-3 was notable for a large placebo effect and a racial influence on that effect as well as an attenuated BP response to RDN. The latter finding has raised procedural considerations, including the anatomical distribution of sympathetic nerves, operator experience, and catheter technology. In light of the conflicting results, further investigation is planned to address some of these issues. RDN has an excellent safety profile, improves nocturnal dipping, and has a beneficial impact on vascular stiffness that is independent of BP reduction. ${ }^{37}$ Thus, this technology may represent an innovative approach to treating resistant hypertension that could potentially reduce the morbidity and mortality risks associated with uncontrolled BP.
Conflict of Interest Disclosure: Dr. Cohen is the site principal investigator for the Medtronic SYMPLICITY HTN-3 study.

Keywords: renal denervation, sympathetic nervous system, resistant hypertension, blood pressure

\section{References}

1. Lewington S, Clarke R, Qizilbash N, Peto R, Collins R, Prospective Studies Collaboration. Age-specific relevance of usual blood pressure to vascular mortality: a meta-analysis of individual data for one million adults in 61 prospective studies. Lancet. 2002 Dec 14;360(9349):1903-13.

2. Lloyd-Jones DM, Evans JC, Levy D. Hypertension in adults across the age spectrum: current outcomes and control in the community. JAMA. 2005 Jul 27;294(4):466-72.

3. Persell SD. Prevalence of resistant hypertension in the United States, 2003-2008. Hypertension. 2011 Jun;57(6):1076-80.

4. Smith SM, Gong Y, Handberg E, et al. Predictors and outcomes of resistant hypertension among patients with coronary artery disease and hypertension. J Hypertens. 2014 Mar;32(3):63543.

5. Claxton AJ, Cramer J, Pierce C. A systematic review of the associations between dose regimens and medication compliance. Clin Ther. 2001 Aug;23(8):1296-1310.

6. Kjeldsen SE, Schork NJ, Leren P, Eide IK. Arterial plasma norepinephrine correlates to blood pressure in middle-aged men with sustained essential hypertension. Am Heart J. 1989 Oct;118(4):775-81.

7. Smith PA, Graham LN, Mackintosh AF, Stoker JB, Mary DA. Relationship between central sympathetic activity and stages of human hypertension. Am J Hypertens. 2004 Mar;17(3):217-22.

8. Ishii M, Ikeda T, Takagi M, et al. Elevated plasma catecholamines in hypertensives with primary glomerular diseases. Hypertension. 1983 Jul-Aug;5(4):545-51.

9. Grassi G, Cattaneo BM, Seravalle G, Lanfranchi A, Mancia G. Baroreflex control of sympathetic nerve activity in essential and secondary hypertension. Hypertension. 1998 Jan;31(1):68-72.

10. Grassi G, Seravalle G, Quarti-Trevano F, et al. Adrenergic, metabolic, and reflex abnormalities in reverse and extreme dipper hypertensives. Hypertension. 2008 Nov;52(5):925-31.

11. Schlaich MP, Kaye DM, Lambert E, Sommerville M, Socratous F, Esler MD. Relation between cardiac sympathetic activity and hypertensive left ventricular hypertrophy. Circulation. 2003 Aug 5;108(5):560-5.

12. Greenwood JP, Scott EM, Stoker JB, Mary DA. Hypertensive left ventricular hypertrophy: relation to peripheral sympathetic drive. J Am Coll Cardiol. 2001 Nov 15;38(6):1711-7.

13. Katholi RE. Renal nerves in the pathogenesis of hypertension in experimental animals and humans. Am J Physiol. 1983 Jul;245(1):F1-14

14. Huan Y, Cohen DL. Renal denervation: a potential new treatment for severe hypertension. Clin Cardiol. 2013 Jan;36(1):10-4.

15. Schlaich MP, Sobotka PA, Krum H, Lambert E, Esler MD. Renal sympathetic-nerve ablation for uncontrolled hypertension. N Engl J Med. 2009 Aug 27;361(9):932-4.

16. Hering D, Lambert EA, Marusic $P$, et al. Substantial reduction in single sympathetic nerve firing after renal denervation in patients with resistant hypertension. Hypertension. 2013 Feb;61(2):45764.

17. Bohm M, Mahfoud F, Ukena C, et al. First Report of the Global SYMPLICITY Registry on the Effect of Renal Artery Denervation in Patients With Uncontrolled Hypertension. Hypertension. 2015 Apr;65(4):766-74. 
18. Tsioufis CP, Papademetriou V, Dimitriadis KS, et al. Catheterbased renal denervation for resistant hypertension: Twenty-four month results of the EnligHTN I first-in-human study using a multi-electrode ablation system. Int J Cardiol. 2015 Aug 7;201:345-50.

19. Sievert H, Schofer J, Ormiston J, et al. Renal denervation with a percutaneous bipolar radiofrequency balloon catheter in patients with resistant hypertension: 6-month results from the REDUCE-HTN clinical study. Eurolntervention. 2015 Feb;10(10):1213-20.

20. Verheye S, Ormiston J, Bergmann MW, et al. Twelve-month results of the rapid renal sympathetic denervation for resistant hypertension using the OneShotTM ablation system (RAPID) study. Eurolntervention. 2015 Feb;10(10):1221-9.

21. Krum H, Schlaich M, Whitbourn R, et al. Catheter-based renal sympathetic denervation for resistant hypertension: a multicentre safety and proof-of-principle cohort study. Lancet. 2009 Apr 11;373(9671):1275-81.

22. Krum H, Schlaich MP, Sobotka PA, et al. Percutaneous renal denervation in patients with treatment-resistant hypertension: final 3-year report of the Symplicity HTN-1 study. Lancet. 2014 Feb 15;383(9917):622-9.

23. Symplicity HTN-2 Investigators. Renal sympathetic denervation in patients with treatment-resistant hypertension (The Symplicity HTN-2 Trial): a randomised controlled trial. Lancet. 2010 Dec 4;376(9756):1903-9.

24. Esler MD, Bohm M, Sievert H, et al. Catheter-based renal denervation for treatment of patients with treatment-resistant hypertension: 36 month results from the SYMPLICITY HTN-2 randomized clinical trial. Eur Heart J. 2014 Jul;35(26):1752-9.

25. Bhatt DL, Kandzari DE, O'Neill WW, et al. A controlled trial of renal denervation for resistant hypertension. N Engl J Med. 2014 Apr 10;370(15):1393-1401.

26. Bakris GL, Townsend RR, Flack JM, et al. 12-month blood pressure results of catheter-based renal artery denervation for resistant hypertension: the SYMPLICITY HTN-3 trial. J Am Coll Cardiol. 2015 Apr 7;65(13):1314-21.
27. Kandzari DE, Bhatt DL, Brar S, et al. Predictors of blood pressure response in the SYMPLICITY HTN-3 trial. Eur Heart J. 2015 Jan 21;36(4):219-27.

28. Mahfoud F, Edelman ER, Bohm M. Catheter-based renal denervation is no simple matter: lessons to be learned from our anatomy? J Am Coll Cardiol. 2014 Aug 19;64(7):644-6.

29. Sakakura K, Ladich E, Cheng Q, et al. Anatomic assessment of sympathetic peri-arterial renal nerves in man. J Am Coll Cardiol. 2014 Aug 19;64(7):635-43.

30. Azizi M, Sapoval M, Gosse P, et al. Optimum and stepped care standardised antihypertensive treatment with or without renal denervation for resistant hypertension (DENERHTN): a multicentre, open-label, randomised controlled trial. Lancet. 2015 Jan 23;385(9981):1957-65.

31. Desch S, Okon T, Heinemann D, et al. Randomized shamcontrolled trial of renal sympathetic denervation in mild resistant hypertension. Hypertension. 2015 Jun;65(6):1202-8.

32. Hering D, Mahfoud F, Walton AS, et al. Renal denervation in moderate to severe CKD. J Am Soc Nephrol. 2012 Jul;23(7):1250-7.

33. Schlaich MP, Bart B, Hering D, et al. Feasibility of catheter-based renal nerve ablation and effects on sympathetic nerve activity and blood pressure in patients with end-stage renal disease. Int J Cardiol. 2013 Oct 3;168(3):2214-20.

34. Bacaksiz A, Uyarel H, Jafarov P, Kucukbuzcu S. Iatrogenic renal artery stenosis after renal sympathetic denervation. Int J Cardiol. 2014 Apr 1;172(3):e389-90.

35. Jaen Aguila F, Mediavilla Garcia JD, Molina Navarro E, Vargas Hitos JA, Fernandez-Torres C. Bilateral renal artery stenosis after renal denervation. Hypertension. 2014 May;63(5):e126-7.

36. Kaltenbach B, Id D, Franke JC, et al. Renal artery stenosis after renal sympathetic denervation. J Am Coll Cardiol. 2012 Dec 25;60(25):2694-5.

37. Brandt MC, Reda S, Mahfoud F, Lenski M, Bohm M, Hoppe UC. Effects of renal sympathetic denervation on arterial stiffness and central hemodynamics in patients with resistant hypertension. J Am Coll Cardiol. 2012 Nov 6;60(19):1956-65. 